Federal Reserve Bank of Dallas

Globalization and Monetary Policy Institute

Working Paper No. 128

http://www.dallasfed.org/assets/documents/institute/wpapers/2012/0128.pdf

\title{
Does the IMF's Official Support Affect Sovereign Bonds Maturities?*
}

\author{
Aitor Erce \\ Bank of Spain \\ September 2012
}

\begin{abstract}
This paper looks at whether the tendency of some governments to borrow short term is reinforced by financial support from the International Monetary Fund. I first present a model of sovereign debt issuance at various maturities featuring endogenous liquidity crises and maturity mismatches due to financial under-development. I use the model to analyse the impact of IMF lending during debt crises on the sovereign's optimal maturity structure. Within the model, although IMF assistance is able to catalyse private flows, this provides incentives for government to issue larger amounts of short-term debt, making the roll-over problem larger. I take the model to the data and find support for the hypothesis that IMF lending leads countries to increase their short-term borrowing. Additionally, I do not find any positive effect of IMF lending on countries' ability to tap international capital markets. These results help explain why a catalytic effect of IMF lending has proved empirically elusive.
\end{abstract}

JEL codes: F33, F34, C33

\footnotetext{
* Aitor Erce, Research Economist, General Directorate of International Affairs, Bank of Spain, Alcala 48, 28014, Madrid, Spain. +34-91-338-5498. aerce@bde.es. I thank Tito Cordella, Giancarlo Corsetti, Javi Diaz-Cassou, Bernardo Guimaraes, Andy Powell, Steven Poelhekke, Sanne Zwart and seminar participants at European University Institute, Bank of Spain, Dutch National Bank and the 7th Latin American Finance Network for valuable comments. Silvia Gutierrez provided superb research assistance. The views in this paper are those of the author and do not necessarily reflect the views of the Bank of Spain, the Federal Reserve Bank of Dallas or the Federal Reserve System.
} 


\section{Introduction}

Debt defaults and restructurings are an unfortunate regularity in sovereign bonds' markets. ${ }^{1}$ More often than not countries facing debt distress had accumulated large amounts of short term and foreign currency denominated debt. Indeed, in most cases, the trigger of the crises was the inability of the sovereign to either roll over or pay back maturing debt. ${ }^{2}$

As part of the crisis-resolution strategy, many episodes featured involvement of the International Monetary Fund (IMF), which took on the role of an International Lender of Last Resort (LOLR). The IMF provided these economies with working capital while they solved their problems. These interventions have both opponents and supporters. The absence of strong evidence regarding a positive impact of official lending has served IMF critics to claim that overestimation of its catalytic role has led the Fund to impose excessively contractive policies (Birds and Rowlands, 2002). Moreover, opponents argue that such policies generate moral hazard both on debtors and creditors, and that the Fund's seniority status is detrimental for the debtor-creditors relationship as it might dilute private obligations (Saravia, 2010). On the opposite side, defenders argue that, by reassuring private creditors about the existence of an ordered exit of the crisis, these interventions could catalyze private flows when most needed (Corsetti et al., 2006). An extensive literature has flourished aimed at measuring the importance of this catalytic effect. At best the evidence is mixed. A majority of studies, either regression analyses or case studies, put in doubt the existence of any such positive effect (Ghosh et al, 2002). ${ }^{3}$

In this paper I analyze a potential channel of influence of the IMF on countries' funding mostly unexplored but that, on light of past experiences, should be well understood: the relation between debt maturity and official financial support programs. Jeanne (2009) presents a general equilibrium model in which the need to roll over external debt disciplines the policies of debtor countries but makes them vulnerable to unwarranted debt crises owing to bad shocks. He shows that some well intentioned policies may have an effect different than the one intended because of the endogeneity of debt structures. For example, taxing dangerous forms of debt leads to increased riskiness of debt in equilibrium. On the empirical side, Mina and Martinez-Vazquez (2002), using aggregate country data, find that IMF lending reduces the countries reliance of short term debt flows. Saravia (2011) presents evidence on the relation between IMF lending and countries' private and public debt maturity choices. Using a sample from

\footnotetext{
${ }^{1}$ Examples include Russia (1998), Argentina (2001), Jamaica (2009) or Greece (2012).

${ }^{2}$ See Rodrik and Velasco (1999) or Jeanne (2004) for models on maturity mismatches.

${ }^{3}$ A catalytic effect has been found in some circumstances. Eichengreen and Mody (2001) find a stronger catalytic effect for intermediate economic fundamentals. Various papers have tested whether different types of capital flows react differently to IMF lending. Edwards (2003) finds no catalytic effect on bond issuance. The opposite is true for Eichengreen et al. (2005), who argue that the IMF's role as a "vigilante" is more likely to manifest in bond markets. Diaz -Cassou et al. (2006) argue that conditionality is the strongest channel of IMF catalysis. Mody and Saravia (2003) find that larger programs associate with stronger catalysis and that a continued IMF presence in a country reinforces this effect. However, if excessively lengthy, such presence can be perceived as a sign of failure, discouraging capital flows. Similarly, Eichengreen et al. (2005) find that, in high-debt countries, is the size of the assistance rather than the presence what attracts private capital. Broto et al. (2011) show that larger availability of Fund resources associates with lower capital flows' volatility .
} 
1990 until 2001, he finds the opposite effect: IMF loans reduce the maturity of newly issued debt. Saravia argues that this is due to the IMF's senior status.

With these observations in mind, I introduce a modification of Corsetti et al (2006) global game model on IMF catalysis, where short term debt is the outcome of financial underdevelopment. This modelling strategy delivers endogenous liquidity crises without resorting to sun-spots. ${ }^{4}$ In the model, which under mild conditions delivers a unique equilibrium, the debt structure, prices and the probability of facing a liquidity crisis are determined simultaneously. As in Broner et al. (2012), equilibrium maturity structure results from tradingoff riskier short term debt and more expensive long term debt. Shorter debt is risky because it must be rolled-over, opening the door to liquidity crises. Long debt is dearer because investors are hit by liquidity shocks and, despite they can liquidate their portfolio using (illiquid) secondary markets, cant recoup the full asset value. Financial development affects interest rates both directly and indirectly (through the maturity).. I then extend the model to assess how a LOLR can affect the maturity profile and the occurrence of crises. In the model, the LOLR minimizes the incidence of liquidity crises by providing official financing. This insurance, however, by reducing the riskiness of short term debt, affect both investors and the Government. If investors have expectations that the IMF will counter a capital flight, they are more likely to roll-over. In this sense the IMF has a catalytic effect. However, by insuring Governments, financial assistance also changes the optimal maturity which, depending on the effect of the assistance on the recovery rate, can bend towards shorter debt, increasing the roll-over problem. The overall effect depends on how IMF lending impacts the debt structure choice.

The model shares most with Corsetti et al. (2006) and Morris and Shin (2006). Corsetti et al. (2006) shows that official lending can strengthen government's incentives to implement costly policies. Moreover, they show that this is an increasing-with-size effect. Similarly, Morris and Shin (2006) show that for catalytic finance to work it needs to be a strategic complement of the government's decision to exert effort, which only happens for intermediate values of the fundamentals. Also Peñalver (2004) includes a debt structure in a model of IMF lending. He shows that subsidized lending induces the borrowing country to exert effort to avoid default. This in turn, by raising future rates of return on investment, encourages larger private capital flows. ${ }^{5}$ De Resende (2007) shows that, if conditionality forces the country to save more, the resulting lower probability of default can induce private lenders to relax their borrowing constraints. The model also shares with the literature on debt structure determination. As in Caballero and Krishnamurthy (2000), financial underdevelopment explains the existence of mismatches. As in Chang and Velasco (2000) or Broner et al. (2012), countries borrow short term because it is regarded as cheaper. ${ }^{6}$

In the second part of the paper, I use a large dataset on sovereign bond issuance to provide empirical evidence on the relation between maturities and IMF interventions. The empirical framework draws mainly from Eichengreen

\footnotetext{
${ }^{4}$ Jeanne (2011) speaks of the black box determining the outcome of the coordination game.

${ }^{5}$ In Peñalver (2004) the only difference between short and long debt is the issuance date.

${ }^{6}$ According to another widely held view, short term debt is a device used by lenders to force governments to commit to good policies. See Rodrik and Velasco (1999) or Kharroubi (2002).
} 
et al. (2001) and Saravia (2011). The evidence, in line with Saravia (2010), shows that the availability of official financing in the form of an IMF treatment represents an incentive to bend towards shorter maturities. Moreover, I find that this effect is especially strong for EFF programs. I also document a negative effect of the size of the assistance on maturity. Lager program (In GDP terms) are accompanied by shorter debt maturities. Finally, wile controlling for sample selection, I find that IMF programs seem to have a negative effect on issuance. This is, again, an increasing-with-size, effect.

Section 1 introduces the benchmark maturity choice model and an extension where international financial assistance is available. Section 2 collects the empirical evidence and, finally, Section 3 concludes. Tables, data sources and the more involved proofs are presented in the Appendix.

\section{A benchmark economy}

There are two different actors; the Government and a continuum of investors. The model evolves over 3 time periods. In period 0, the Government has a production opportunity for which it needs an amount $I$ of funds. Government finances it by issuing short $(S)$ and long $(L)$ term debt, so that $I=S+L$. The short and the long interest rates, defined by $r_{s}$ and $r_{L}$ respectively, are determined by a non-arbitrage condition. ${ }^{7}$ As in Diamond and Dygbig (1983), ex-ante identical investors are uncertain about their time preference. They might become impatient and value interim-period consumption only. Investors' only know that with probability $\lambda$ they will be of the impatient type and with probability $(1-\lambda)$ will derive the same utility from consumption at any time. ${ }^{8}$

$$
U\left(c_{1}, c_{2}\right)=\left\{\begin{array}{cc}
c_{1} & \text { prob. } \lambda \\
c_{1}+c_{2} & \text { prob. }(1-\lambda)
\end{array}\right.
$$

I assume that, in the interim period, the Government must roll its short term debt over and offers investors a premium to delay repayment. Investors must decide wether to accept or flee. In case of need the Government can tap an uncertain amount of resources $\theta$. If the roll-over fails, the government defaults and faces a reputational cost. ${ }^{9}$ Investors' course of action in period 1 will depend on the realization of both $\lambda$ and a private signal on $\theta$ they receive. Secondary market for long term debt also opens in period 1. Impatient investors can use it to adjust their portfolio. In the last period payments are realized.

The information structure is the following. At time 0 , all that is known is that Government's interim-period resources are uniformly distributed, $\theta \sim U$ $[-\eta, 1+\eta]$ with $\eta \in[0, \infty)$, that the probability of being impatient is $\lambda$, and the roll-over premium. In period 1 , investors receive private signals about $\theta$, $x_{i}=\theta+\varepsilon_{i}$, with $\varepsilon_{i} \sim U[-\varepsilon, \varepsilon]$.

Before moving to the determination of the maturity structure, I describe how the roll-over and the secondary market, it's main determinants, work.

\footnotetext{
${ }^{7}$ In equilibrium investors must be indifferent between holding any maturity.

${ }^{8} \mathrm{I}$ will also term impatient investors as liquidity constrained ones, and the ex-ante uncertainty about the discount factor as liquidity risk.

${ }^{9}$ This cost could be understood as sanctions, a reputational cost or the loss of future oputput. The specific functional form is specified later.
} 


\section{Roll-over Game}

Investors facing the roll over decision are engaged in a coordination game. There are strategic complementarities, as investors' payoffs depend on the action taken by the others. The payoff for an investor who decides to roll-over is

$$
\Pi^{R O}=\left\{\begin{array}{cc}
\left(1+r_{s}\right) \rho & \text { if } \quad \theta^{*} \geq f\left(\theta^{*}\right) \\
0 & \text { otherwise }
\end{array}\right.
$$

The (ex-ante known) roll-over premium is $\rho>1$. In the event of a default, investors get nothing. Conversely, if an investor withdraws her payoff is

$$
\Pi^{N R O}=\left\{\begin{array}{ccc}
\left(1+r_{s}\right) & \text { if } & \theta^{*} \geq f\left(\theta^{*}\right) \\
\left(1+r_{s}\right) \beta & & \text { otherwise }
\end{array}\right.
$$

where $\beta$ stands for the recovery rate in a default event. Unconstrained investors use their private information about the liquidity position of the Government, $x_{i}$, to decide whether to roll-over or flee. ${ }^{10}$ The project will only be successful if the government has enough resources to cover the gap created by a lack of willingness from investors to roll-over maturing debt. ${ }^{11}$ Such condition is fulfilled whenever $\theta>f$, where $f$ denotes the proportion of investors fleeing.

I will be interested in equilibria in trigger strategies. ${ }^{12}$ This amounts to find a value $\theta^{*}$ which generates a distribution of signals such that there is a unique value $x^{*}$ below which investors prefer to withdraw. First, I set a equation where the value of $\theta$ generates a selling pressure matching itself,

$$
\theta^{*}=f\left(\theta^{*}\right)=\lambda s+(1-\lambda) s \frac{x^{*}+\varepsilon-\theta^{*}}{2 \varepsilon},
$$

$f\left(\theta^{*}\right)$ denotes the proportion of investors who choose to flee for liquidity $\theta^{*}$. In addition to the non-liquidity constrained investors with signals below $x^{*}$, all liquidity constrained investorsalso flee, which accounts for the term $\lambda s$.

Note that the marginal investor must be indifferent between rolling over or fleeing. This is implies that $\Pi^{R O}\left(x^{*}, \theta^{*}\right)=\Pi^{N R O}\left(x^{*}, \theta\right)$. After some algebra,

$$
P\left(\theta \geqslant \theta^{*} \mid x^{*}\right)=\frac{\beta}{\rho+\beta-1} .
$$

As shown in the Appendix, further manipulation delivers

$$
\frac{x^{*}+\varepsilon-\theta^{*}}{2 \varepsilon}+2 \varepsilon \Psi\left(\theta^{*}, x^{*}, \eta, \varepsilon\right)=\frac{1+2 \eta+2 \varepsilon}{1+2 \eta-2 \varepsilon} \mu
$$

where $\Psi\left(\theta^{*}, x^{*}, \eta, \varepsilon\right)=\frac{\left(\frac{x^{*}+\varepsilon-\theta^{*}}{x^{*}+\varepsilon+\eta}\right)+\left(\frac{1+\eta-\theta^{*}}{1-x^{*}+\varepsilon+\eta}\right)}{1+2 \eta-2 \varepsilon}$ and $\mu=\frac{\beta}{\rho+\beta-1} \in(0,1)$.

\footnotetext{
${ }^{10}$ As required by the solution tecnique, the problem has two dominance regions. Whenever $\theta>1$, the dominant strategy is to roll-over. Conversely, whenever $\theta<0$ liquidation is unaviodable and the dominant strategy is to flee.

${ }^{11}$ The fundamentals could include tax revenues, reserves or any other instruments that may give liquidity to the government.

${ }^{12}$ In this enviroment of strategic complementarities, under some conditions on the precision of information, there is a unique equilibrium trigger straregy, which is, moreover, the unique equilibrium of the game (see Morris and Shin, 1998).
} 
Equations (1.1) and (1.2) uniquely determine $\theta^{*}$ and $x^{*} \cdot{ }^{13}$ In order to work with an analytical solution, the rest of the analysis focuses on the case in which the private signals become arbitrarily precise, $\frac{\varepsilon}{\eta} \rightarrow 0$. In such case, $x^{*} \rightarrow \theta^{*} .{ }^{14}$ Substitution of (1.2) back into (1.1) delivers:

$$
\theta^{*}=\lambda s+\mu s-\lambda s \mu \text {. }
$$

\section{Secondary Market for Long Term Debt}

Secondary market opens after investors learn their type, as the liquidity shock creates incentives to buy and sell. Sellers are those investors hit by the liquidity shock, as they get no utility from holding the bond to maturity. On the other side of the market, buyers' valuation of the bond is $\left(1+r_{L}\right) P\left(\theta \geqslant \theta^{*} \mid x^{*}\right)$. This different valuation provides a opportunity for trade.

If $\theta<\theta^{*}$, the only price at which investors can sell the asset is 0 . Conversely, when $\theta>\theta^{*}$ there will be meaningful transactions in the secondary market. Assuming that unconstrained investors are deep-pocketed and using a non-arbitrage argument the price of the bond is $p_{L}=1+r_{L}$.

As in Caballero and Krishnamurthy (2000), market imperfections prevent sellers from recovering the asset's full value. A proportion $(1-\kappa)$ of the sale price is lost. ${ }^{15}$ Thus, although the price of the asset, $p_{L}$, is fair in the sense that no-one who buys it can make profits above the market rate, the seller receives only $\kappa p_{L}$. Long bonds are subject to price risk.

\section{Interest rates}

Equilibrium interest rates are derived from the fact that, in equilibrium, both bonds must give the same expected utility as the safe asset, which guarantees one unit of consumption, $r^{\text {safe }}=0$. For short term bonds this implies

$$
\left(1+r_{s}\right) P\left(\theta \geq \theta^{*}\right)[(1-\lambda) \rho+\lambda]+\left(1+r_{s}\right) \beta P\left(\theta \leq \theta^{*}\right)=1 .
$$

So that

$$
\left(1+r_{s}\right)=p_{s}^{-1}=\frac{1}{h[(1-\lambda) \rho+\lambda-\beta]+\beta},
$$

where $h=P\left(\theta \geq \theta^{*}\right)=\frac{1+\eta-\lambda s-\mu s+\lambda \mu s}{1+2 \eta}$. Similarly, for long term bonds the following must hold

$$
\left(1+r_{L}\right) P\left(\theta \geq \theta^{*}\right)(1-\lambda)+\kappa\left(1+r_{L}\right) P\left(\theta \geq \theta^{*}\right) \lambda=1 .
$$

So, the implied long term interest rate is $1+r_{L}=\frac{1}{(1-\lambda+\lambda \kappa) h}$.

As the maturity structure tilts to short term debt, thereby increasing the probability of a liquidity crises, the interest rates offered need to increase.

$$
\frac{\partial r_{L}}{\partial s}>0 \& \frac{\partial r_{s}}{\partial s}>0 \forall s
$$

\footnotetext{
${ }^{13}$ All that is needed for uniqueness is that $\frac{\varepsilon}{\eta}$ is small enough (see Appendix).

${ }^{14}$ This delivers a closed form solution while the effect of strategic uncertainty remains.

${ }^{15}$ This can be understood as fees paid to intermediaries, bid-ask spreads or, else, as the cost of looking for a buyer. The parameter $\kappa$ represents the degree of development/liquidity of the market. More developed markets should have larger values of $\kappa$.
} 


\section{Government's Optimal Debt Structure}

Short term debt issuance increases both interest rates and, by increasing the size of the coordination problem, the probability of observing the investment ending in a failure. From the point of view of the Government, however, short term debt is cheaper in expected terms. This is so because liquidity constrained investors value future payments less than the Government. This trade off between risk and cost is at the root of the problem described below.

The net outcome from the project, $Y(\theta)$, is composed of two parts,

$$
Y(\theta)=\left\{\begin{array}{lll}
F(I) & \text { if } & \theta \geq \theta^{*} \\
D C & \text { if } & \theta<\theta^{*}
\end{array}\right.
$$

The production function, $F(I)$, is standard: $F^{\prime}(I)>0$ and $F^{\prime \prime}(I)<0$. The default cost, $D C$, equals $-\left(c_{1} S+c_{2} L\right)$. This collects outlays after a default due to demands by lenders. ${ }^{16}$ Default cost is modelled in an asymmetric fashion. As default comes first on maturing debt, potentially triggering further problems, I assume that $c_{2}<c_{1} \cdot{ }^{17}$ The Government problem can be summarized as follows

$$
\begin{gathered}
\max _{s} E(Y(\theta)-F C) \\
\text { s.t. } \quad s \geqslant 0 \\
s \leq 1
\end{gathered}
$$

where $E(F C)=S+\frac{L}{1+\lambda \kappa-\lambda}$ stands for the financing cost and $E(Y(\theta))=$ $F(I) P\left(\theta \geq \theta^{*}\right)-\left(c S+c_{2} I\right) P\left(\theta \leq \theta^{*}\right)$ is the expected net outcome from the project. Note that the financing cost is not independent of the maturity choice. The solution to this constrained maximization problem is

$$
\begin{array}{ll}
\text { If } & \bar{B}>0 \text { then } s^{*}=1 \\
\text { If } & \underline{B}<0 \text { then } s^{*}=0
\end{array}
$$

Finally, if $\bar{B}<0$ and $\underline{B}>0$ then

$$
s^{*}=\frac{(1+2 \eta)(\lambda-\lambda \kappa)}{2 c(1+\lambda \kappa-\lambda) \Gamma}-\frac{F(I)}{2 c I}-\frac{c_{2}}{2 c}-\frac{\eta}{2 \Gamma}
$$

with $\Gamma=(\lambda+\mu-\lambda \mu), \bar{B}=\frac{(\lambda-\lambda \kappa) I}{1+\lambda \kappa-\lambda}-\left(F(I)+2 c I+c_{2} I\right)\left(\frac{\lambda+\mu-\lambda \mu}{1+2 \eta}\right)-\frac{c I \eta}{1+2 \eta}$ and $\bar{B}=\frac{(\lambda-\lambda \kappa) I}{1+\lambda \kappa-\lambda}-\left(F(I)+2 c I+c_{2} I\right)\left(\frac{\lambda+\mu-\lambda \mu}{1+2 \eta}\right)-\frac{c I \eta}{1+2 \eta}$.

Note that $\bar{B}<\underline{B} .{ }^{18}$ The elements in $\bar{B}$ represent, respectively, the reduction in the financing cost, the reduction on the expected return and the increase in default costs when all the investment is financed through short term debt. Thus, when $\bar{B}>0$, the reduction on the financing cost is bigger than the combined increase on the expected returns and default costs, and it is optimal to issue only short term debt. If, instead, the reduction of the financing cost from issuing

\footnotetext{
${ }^{16}$ Litigation costs have been widely used. See Miller and Zhang (2000), Bris and Welch (2001), Roubini and Setser (2004) or Jeanne (2004).

17 This assumption guarantees the existence of an interior maximum.

${ }^{18}$ The complete Kuhn-Tucker program for the Government can be found in the Appendix.
} 
short term debt (first term in $\underline{B}$ ) is smaller than the reduction on the revenues (last two terms in $\underline{B}$ ), then it is optimal not to have short term debt at all $\left(\underline{B}<0\right.$ and $\left.s^{*}=0\right)$.

It is straightforward that lower investment returns, lower litigation costs, higher roll over premia, lower recovery rates and less developed secondary markets lead to debt structures with more short term debt.

\section{Liquidity Assistance: Lender of Last Resort}

I augment the game with an additional player following the symmetric approach to global games with heterogeneous players developed in Bannier (2005). This easily implementable approach maintains the model's ability to highlight the major issues related with this policy tool. The lender of last resort (LOLR) acts as follows. Conditional on a private signal $y$ about $\theta$ it receives in the interim period, must decide whether to grant assistance of size $A .{ }^{19}$ The LOLR signal is uniformly distributed, $y \sim U(\theta-v, \theta+v)$. As in Corsetti et al. (2006) and Rochet and Vives (2004), I assume a non-monetary revenue function for the LOLR. ${ }^{20}$ When a country succeeds and there is no default the LOLR obtains utility $S$. If, instead, the final outcome is a default, the LOLR obtains utility $-D$. Using this assumptions, the LOLR's indifference condition is

$$
S P\left(\theta>\theta_{A}^{*} / y^{*}\right)-D P\left(\theta<\theta_{A}^{*} / y^{*}\right)=0 .
$$

The recovery rate might be affected by amount of funds provided, $\beta=\beta(A)$. This changes investors' pay-off from fleeing

$$
\Pi^{N R O}=\left\{\begin{array}{c}
\left(1+r_{s}\right) \quad \text { if } \quad \theta_{A}^{*} \geq f\left(\theta_{A}^{*}\right) \\
\left(1+r_{s}\right) \beta(A) \text { if } \theta_{A}^{*} \leq f\left(\theta_{A}^{*}\right) \text { and } y \geq y^{*} \\
\left(1+r_{s}\right) \beta \text { if } \theta_{A}^{*} \leq f\left(\theta_{A}^{*}\right) \text { and } y<y^{*}
\end{array}\right.
$$

Also the mass condition changes to include an element reflecting the potential liquidity assistance

$$
\theta_{A}^{*}+A\left(\frac{\theta_{A}^{*}+\nu-y^{*}}{2 \nu}\right)=\lambda s+(1-\lambda) s \frac{x^{*}+\varepsilon-\theta_{A}^{*}}{2 \varepsilon} .
$$

As before, $\Pi^{R O}\left(x^{*}, \theta_{A}^{*}\right)=\Pi^{N R O}\left(x^{*}, \theta_{A}^{*}\right)$. Assuming that $\varepsilon$ and $v$ are arbitrarily small delivers the equilibrium values for $\theta_{A}^{*}$ and $s_{I M F}^{*}$ :

$$
\theta_{A}^{*}=\lambda s+(1-\lambda) s \mu_{I M F}-J,
$$

and

$$
s_{I M F}^{*}=\frac{(1+2 \eta)(\lambda-\lambda \kappa)}{2 c(1+\lambda \kappa-\lambda) \Gamma_{I M F}}-\frac{F(I)}{2 c I}-\frac{c_{2}}{2 c}-\frac{\eta}{2 \Gamma_{I M F}}+\frac{J}{2 \Gamma_{I M F}}
$$

where $\mu_{I M F}=\frac{\beta(A)}{\rho+\beta(A)-1}, J=A \frac{S}{D+S}$ and $\Gamma_{I M F}=\left(\lambda+\mu_{I M F}-\lambda \mu_{I M F}\right){ }^{21}$

The presence of the LOLR affects not only the investors incentives to rollover but also the Government's preferred maturity structure.

\footnotetext{
${ }^{19}$ Assuming that moves occur simultaneously eliminates the possibility that the IMF uses lending to confer information. Zwart (2006) presents this signaling device in a model without debt structure and shows that signaling is a mixed blessing. It only helps when fundamentals are strong. The same mechanism would be present here.

${ }^{20}$ These simple pay-offs guarantee the existence of strategic complementarities.

${ }^{21}$ See Bannier (2005) for details on existence and uniqueness of the equilibrium.
} 


\section{"Catalytic" effect and the maturity mismatch}

If $\beta$ is not affected by liquidity assistance $(\beta(A)=\beta), \mu=\mu_{I M F}$ and the pay-off from fleeing collapses to the original one. In this case, for a given $s$,

$$
\theta_{A}^{*}=\lambda s+(1-\lambda) s \mu-J .
$$

The presence of the LOLR decreases all thresholds, $\theta_{A}^{*}<\theta^{*}$ and $x_{A}^{*}<x^{*}$. This is the catalytic effect of the assistance. By reassuring investors, assistance avoids crises for a wider range of situations. Moreover, the greater the size of the assistance, the greater this effect.

$$
\frac{\partial \theta_{A}^{*}}{\partial A}<0
$$

However, when the LOLR is present the optimal maturity choice becomes,

$$
s_{I M F}^{*}=s^{*}+\frac{J}{2 \Gamma} .
$$

Not surprisingly, $s$ increases in the presence of a LOLR, $s_{I M F}^{*}>s^{*}$. If the government thinks that the LOLR is likely inject money when needed, it has an incentive to increase the proportion of short term debt and profit from the lower interest rate to be paid. In this model, due to the linearity of the uniform distribution, $\theta_{A}^{*}-\theta^{*}=-\frac{J}{2}<0$. Therefore, the total effect of the assistance is to reduce both, the probability of default and interest rates, $r_{i}>r_{i}^{I M F}$.

\section{Increased recovery rates and the "rush for the exits" problem}

Suppose instead that the liquidity assistance, by raising the availability of resources or spurring economic growth, increases the recovery rate $\beta(A)>\beta$. In this case, the assistance can generate a "rush for the exits" effect, with investors taking advantage of the Fund's support to flee the country.

Proposition 1 For a given debt structure, the lower the size of the program, $A$, and the higher the recovery rate for a given size of the assistance, $\beta(A)$, the easier it becomes that the program will be unable to catalyze funds, $\theta_{A}^{*}>\theta^{*}$.

Proof. Note that the difference between $\theta_{A}^{*}$ and $\theta^{*}$ is

$$
\theta_{A}^{*}-\theta^{*}=\left(\Gamma_{I M F}-\Gamma\right) s-J
$$

Define $\alpha(\beta)=\frac{\Gamma_{I M F}}{\Gamma}>\Gamma_{I M F}$ and $s=(a-d) \Gamma^{-1}-b .{ }^{22}$ For $\theta_{A}^{*}>\theta^{*}$ the following must hold,

$$
\alpha(\beta)(a-d)-b \Gamma_{I M F}>A \frac{S}{S+D} .
$$

It is straightforward that there exist $(\alpha(\beta), A)$ such that the above inequality holds. Note also that the lower $A$ is the easier the above inequality holds. One just need to realize that $\frac{\partial \alpha(\beta)}{\partial \beta(A)}>0$ to obtain the result regarding the recovery rate. Define $\widehat{s}=\frac{J}{(1-\lambda)\left(\mu_{I M F}-\mu\right)}$. Whenever $s>\widehat{s}$, the capital flight will increase as a result of IMF's assistance.

$$
{ }^{22} a=\frac{(1+2 \eta)(\lambda-\lambda \kappa)}{2 c(1+\lambda \kappa-\lambda)}, b=\frac{F(I)}{2 c I}+\frac{c_{2}}{2 c} \text {, and } d=\frac{\eta}{2} .
$$


This is, again, a partial equilibrium result. The impact of the LOLR on $\beta$ and $\theta^{*}$ will, in turn, affect the Government's optimal debt composition. The next proposition shows how the LOLR's impact on recovery rates affects the optimal debt structure.

Proposition 2 As liquidity assistance raises incentives for investors to flee, prospective bail-outs by the IMF will lead sovereigns issue larger amounts of long term debt.

Proof. Comparison of equations (1.4) and (2.4) using (2.5) leads to

$$
s_{I M F}^{*}-s^{*}=\left(a-d+\frac{J}{2}\right)\left(\frac{1}{\Gamma}-\frac{1}{\Gamma_{I M F}}\right)
$$

It is enough to note that the first term is always positive while the second is always negative.

One can compute the total impact on stability to get

$$
\theta_{A}^{*}-\theta^{*}=b\left(\Gamma-\Gamma_{I M F}\right)-\frac{J}{2}
$$

When official assistance guarantees higher recovery rates the sovereign has incentives to reduce short term debt issuance and mitigate the impact of the "rush for the exits" effect.

\section{Empirical Evidence}

This section uses data on primary issuance to present evidence on the impact of IMF bail-outs on the sovereigns' bonded debt structure. The exercise is carried out by pooling information on individual bonds to create quarterly indicators. Individual maturity observations were averaged into quarterly measures using as weights the specific size of each bond. The analysis focuses on the presence of the IMF, but also considers the impact of the size of the financing program and distinguishes effects depending on the type of program signed. Given the well grounded concerns regarding then endogeneity between maturity and IMF lending, the effect of the IMF on bonds maturity is also studied using an instrumental variables approach. Finally, in line with previous studies on the determinants of bond spreads (Eichengreen et al., 2001), I perform the analysis while controlling for potential sample selection biases.

\section{Data}

Data on bond characteristics comes from DCM Analytics (Dealogic). I collected information regarding the maturity, spread, issued amount, coupon type, market of issuance, credit rating and currency denomination of the bonds. The analysis focuses on fixed coupon bonds issued on international markets on a foreign currency and for which country credit ratings were available. From this source, after applying the above mentioned criteria, I obtained almost 2300 observations of public bonds issued by 46 developing economies from 1995 to $2008 .^{23}$

\footnotetext{
${ }^{23}$ See Appendix for a full list of countries.
} 
Data on IMF interventions includes the program duration, the type of program and the size of the assistance. It was obtained from the International Monetary Fund. ${ }^{24}$ We restrict our attention to two types of programs, SBA and EFF. These programs are commonly used to address Balance of Payments problems and liquidity crises. Overall there are 70 new programs, divided into 58 SBA programs and 12 EFF agreements.

Credit ratings and information on sovereign defaults were obtained from Standard \& Poor's. Data coming from the Paris Club of official creditors was used to construct our indicator on Paris Club agreements. International liquidity is proxied in two ways. First,I use a quantity index with base in 1990, that pulls together country data about the ratio of M2 (or reserves when M2 was not available) to GDP (Erce, 2008). Additionally, I use the High Yield spread, coming from Credit Suisse, as a price indicator of liquidity conditions. Data on voting alignment with the US come from Dreher and Stumn (2006)and the index of democracy from Freedom House. Banking crises data comes from Laeven and Valencia (2008). Data on IMF resources (total and individual quotas, borrowing agreements and credit outstanding) all come from the International Monetary Fund. ${ }^{25}$ Table A.1 collects the correlation between the various macroeconomic variables used in the analysis and the maturity variable.

Figure 1 and Table A.2 further describe the data at hand. According to Figure 1, issuance has been higher in countries without IMF programs in all of our sample years but 2002. However, at least from this graph, there is not a clear pattern regarding differences in the maturity of bonds issued with or without IMF presence. Table A.2 compares issuance and maturities around bank crises and sovereign debt crises with that in normal times, both for countries under IMF programs and for countries not under the Fund's auspice. During banking crises times countries seem to issue more debt when under IMF treatment, although the bonds issued have a similar maturity. Interestingly, when faced with a debt crisis the pattern is significantly different. In those situations, countries with ongoing IMF programs tap the markets less often and do it placing maturities rather lower than those of countries facing a debt crises without IMF support. During times with no debt nor bank crises, countries without an IMF program tap markets more often.

\section{Econometric Analysis}

\section{Debt maturity and IMF interventions}

In order to asses the impact of IMF interventions on the observed debt structure I analyze the determinants of sovereign bonds maturity using a panel data model with fixed effects and robust standard errors,

$$
M_{i t}=\beta X_{i t}+\alpha I M F_{i t}+\varepsilon_{i t}
$$

where $M_{i t}$ stands for the weighted maturity of bonds issued by country $i$ at time $t$. The macroeconomic controls: weighted average spread, credit rating, our quantity indicator of global liquidity and bank and debt crises are collected

\footnotetext{
${ }^{24}$ I thank Xabier Serra for kindly sharing his dataset on IMF programs.

${ }^{25}$ Miguel de las Casas kindly provided me with this data.
} 
in $X_{i t}{ }^{26}$ This paper is mostly interested with the sign and significance of $\alpha$, the coefficient collecting the impact of the IMF on the observed maturity. As detailed below, the variable $I M F_{i t}$ will collect not only when the IMF is present, but also the size of the assistance program or the specific type of program.

The results of this first approach can be found in Table 2.a and Table 2.b in the Appendix. The first 3 columns in Table 2.a present the benchmark model and an extension of it including the IMF presence indicator. The results show a positive relation between observed maturities and the spreads of the bonds. ${ }^{27}$ The credit rating and the observed maturity have a weak relation. ${ }^{28}$ The global liquidity indicator is positively related to maturity, meaning that ampler availability of funds leads to bonds on longer maturities being issued. The two crises indicators signal to a maturity difference between banking and debt crises. The later seem to feature issuances on longer maturities. The result regarding the IMF presence dummy are weak and signal to the absence of any effects from official financing on the observed maturity of bonds. Columns 1 and 3 in Table 2.b contain the results of the OLS estimates but replacing the IMF presence indicator, first by two indicators that allow to distinguish the effect of SBA programs from that of EFF programs, and then by using a measure of the relative size of the ongoing program. Interestingly the results show that it is EFF programs, as opposed to SBA programs, the ones accompanied by issuance in shorter maturities (column 1, Table 2.a). Also the size indicator has a highly significant negative relation with maturity (column 3, Table 2.a), indicating that larger programs lead to significantly shorter international bonds being issued. ${ }^{29}$

\section{Instrumenting IMF presence}

The fact that countries likely to need IMF support also tend face some sort of economic distress raises concern regarding the validity of the relation between maturities and IMF support. Given that maturities are related to crises (Broner et al., 2012) and that crisis are associated with IMF lending, it could be the case that we attribute to the IMF the effect of other factors. To get around this critique, I also perform the analysis using an instrumental variables approach. I implement this approach in two steps. First, I estimate the likelihood of receiving an IMF treatment by means of a probit model

$$
\begin{gathered}
I_{i t}^{I M F}=\left\{\begin{array}{lll}
1 & \text { if } & I M F_{i t}^{*}>0 \\
0 & \text { if } & I M F_{i t}^{*} \leq 0
\end{array}\right. \\
I M F_{i t}^{*}=\Phi X_{i t}^{I M F}+w_{i t}
\end{gathered}
$$

The indicator $I_{i t}^{I M F}$ takes a value of one whenever an IMF program is ongoing. The model controls for macroeconomic developments by including the issuer's

\footnotetext{
${ }^{26}$ Bussiere and Ristiniemi (2012) argue that credit ratings contain almost teh same amoutn of informationn regarding economic distress than the commonly used macroeconmic indicators.

${ }^{27}$ Broner et al. (2012) focus on understanding the demand side and find a negative relation. Erce (2008) uses a structural model and finds a positive relation between spreads and maturities when analyzing the investors' maturity supply.

${ }^{28}$ Hale (2001) obtains a similar result.

${ }^{29}$ Notice that among the conditionality imposed on countries by the IMF it is common to find restrictions on short term debt issuance. This should bias the results towards finding a positive relation, thus reinforcing the negative effect just described.
} 
credit rating and various crisis indicators. In order to instrument the IMF variable I follow previous contributions. As Dreher and Vaubel (2004) and Copelovich (2004), I include as determinants of IMF lending the total amount of resources available to the Fund. I divide them in quotas, which are the standard resources, and borrowing agreements. These agreements allow the Fund to raise temporarily, and without changing quotas, additional resources. I also include a measure of available resources. The inclusion of these variables is justified on grounds that self-interested bureaucrats at the IMF have incentives to provide lending. This interest is likely to be larger, the more resources the Fund has at it's disposal. I also include indicators of engagement with the Paris Club, the countries' quota at the IMF, and indicator of alignment with the US in United Nation's voting rounds and a democracy index. ${ }^{30}$ In the second step I reestimate the maturity equation replacing $I_{i t}^{I M F}$ by it's estimated value, $\widehat{I M F}_{i t}^{*}$.

The results for the first step are presented in Table 1. As expected, we find a negative relation between ratings and IMF programs,. Better rated countries are less likely to enter into an IMF program. Results show that countries suffering banking crises are more likely to approach the Fund. The same does not hold true for sovereign debt crises. ${ }^{31}$ Most of our instruments have the expected sign and are highly significant.

Tables 2. $a$ and 2.b contain the results corresponding to the second step. The last column in Table 2. $a$ presents the results when we instrument the IMF presence indicator. The results show now a highly significant and negative relation between IMF programs and sovereign bonds' maturity. Similarly, columns 2 and 4 in Table 2.b present the results when instrumenting the program type indicators and when instrumenting the program size, respectively. The results confirm that EFF programs and larger program amounts accompany shorter maturities.

\section{Tackling sample selection: Modeling the Issuance Decision}

Participation in international bond markets has risen over time. If the factors driving debt maturity affect also market access, OLS estimates of the relationship between maturities and these factors could be biased. This is the well known sample selection problem. To get around it I use a Heckman model to jointly estimate the issuance decision and the maturity choice,

$$
\begin{gathered}
I_{i t}=\left\{\begin{array}{lll}
1 & \text { if } & I_{i t}^{*}>0 \\
0 & \text { if } & I_{i t}^{*} \leq 0
\end{array}\right. \\
I_{i t}^{*}=\Psi X_{i t}^{I}+\tau \widehat{I M F}_{i t}^{*}+v_{i t} \\
M_{i t}=\beta X_{i t}+\alpha \widehat{I M F}_{i t}^{*}+\varepsilon_{i t}
\end{gathered}
$$

\footnotetext{
${ }^{30}$ According to Vreeland (2005) countries where the political system has more veto power are more likely to have IMF programs. SImilarly, Edwards and Santaella (1993) find that dictatorial regimes are more likely to engage with the IMF. Similarly, Tacker (2000) and Barro and Lee (2005) argue that political proximity to the US is important to explain IMF lending. Barro and Lee (2005) and Saravia (2011) argue that a country's quota at the IMF is also a significant determinant of IMF financial support.

${ }^{31}$ This may be due to the more stringent conditions that the Fund requests in order to engage with countries with outstanding external arreas (see Diaz-Cassou et al, 2008).
} 
Access to financial markets in a given quarter is defined by binary variable, $I_{i t}$, that takes value one when country $i$ tapped the market on period $t .{ }^{32}$ Along with the credit rating, our price-based measure of global liquidity and the IMF variables, the model contains the ratio of reserves to imports, which gives an accurate picture of the country's liquidity situation. Both equations are estimated simultaneously using maximum likelihood. In this case, both $\alpha$ and $\tau$ contain information relevant for the question at hand. While $\alpha$ still explains how the IMF affects debt maturity, the coefficient $\tau$ collects the effect, if any, that IMF lending has in countries' ability to tap international capital markets.

Results can be found in Table 3 the Appendix. In all cases the coefficients associated with the credit rating, global liquidity and the weighted spread had the expected signs. The estimation again finds support for the scenario in which IMF lending, specially through EFF programs, reduces the observed maturity of sovereign bonds. Moreover, this effect is again increasing wit the size of the official program. Additionally, we can say something about the effect of IMF lending on Governments' ability to tap international markets. The results point to a lower probability of issuance whenever a country is under an EFF program and when the program size increases. It should be noted, however, that it might well be that, to the extent that the sovereign's financing needs are reduced after signing a program with the Fund, this results stems from voluntary decisions and not from a crowding out effect by the IMF on private lenders.

\section{Conclusions}

In this article I have analyzed, both empirically and theoretically, the impact of IMF assistance on supported countries' debt maturity structure. To set the stage of the analysis, I introduced a model in which the absence of well-developed secondary markets, combined with investors' uncertainty regarding their preferred investment horizon, make governments more willing to issue short term debt. Within the model, short term borrowing can become heavier if there are expectations of an IMF bail-out in the event of a liquidity crisis. Two effects are at play. On the one hand, investors feel reassured if they believe the IMF will come into action if a crisis arises. This "insurance" leads investors to require lower short term interest rates, creating an incentive for sovereigns to borrow larger amounts in a short-term basis. On the other hand, the fresh funds granted by the IMF can lead investors to expect a higher recovery rate if they decide flee. This can lead to a rush for the exits, with a larger proportion of investors not accepting to roll-over. This effect gives governments incentives to lengthen their debt and avoid roll-over problems.

The empirical exercise shows that IMF financial support associates with the public sector issuing debt in shorter maturities. This effect is especially significant for EFF programs. Moreover, I find that the impact increases along with the size of the program. These results could be rationalized using the seniority argument described before and point to the need for the IMF to make it clearer that its support is likely to improve the recovery rate also for private creditors.

\footnotetext{
${ }^{32}$ Note that I am pooling together decisions both uncosntrained and by credit rationed governments. One could use disequilibrium models (Maddala and Nelson, 1974) to understand when selection is voluntary.
} 


\section{Appendix I}

\section{Updated Beliefs}

Recall that $\theta \sim U[-\eta, 1+\eta]$ stands for the fundamentals and $x \mid \theta \sim U[\theta-\varepsilon, \theta+\varepsilon]$ is a private signal about $\theta$. Here I show how the updating process generates $P\left(\theta>\theta^{*} \mid x^{*}\right)$. We know that $\phi(\theta)=\frac{1}{1+2 \eta}$ and that $\phi(x \mid \theta)=\frac{1}{2 \varepsilon}$, where $\phi$ stands for the density function. Rational investors use Bayes rule to update beliefs according to $\phi(\theta \mid x)=\frac{\phi(x \mid \theta) \phi(\theta)}{\int_{\Delta(\theta)} \phi(x \mid \theta) \phi(\theta) d \theta}$, where $\Delta(\theta)=\{\theta \mid \theta \in[\max (x-$ $\varepsilon,-\eta), \min (x+\varepsilon, 1+\eta)]\}$. This defines three different cases, with the signal falling in any of the extremes or falling relatively centered.

Let's start with the case in which the signal is relatively small. In this case, $\Delta(\theta)=\{\theta \mid \theta \in(-\eta, x+\varepsilon)\}$ and the conditional density can easily be computed to be $\phi(\theta \mid x)=\frac{1}{x+\varepsilon+\eta}$. Analogously, for very large signals, $\Delta(\theta)=$ $\{\theta \mid \theta \in(x-\varepsilon, 1+\eta)\}$, with a density function $\phi(\theta \mid x)=\frac{1}{1-x+\varepsilon+\eta}$. Finally, when $\Delta(\theta)=\{\theta \mid \theta \in(x-\varepsilon, x+\varepsilon)\}$, the density is $\phi(\theta \mid x)=\frac{1}{2 \varepsilon}$. The next is step is using these different densities to compute $P\left(\theta>\theta^{*} \mid x^{*}\right)$,

$$
\begin{aligned}
& P\left(\theta \geqslant \theta^{*} \mid x^{*}\right)=P\left(\theta \geqslant \theta^{*} \mid x^{*}<-\eta+\varepsilon\right) P\left(x^{*}<-\eta+\varepsilon\right)+ \\
& P\left(\theta \geqslant \theta^{*} \mid x^{*} \in(-\eta+\varepsilon, 1+\eta-\varepsilon) P\left(x^{*} \in(-\eta+\varepsilon, 1+\eta-\varepsilon)+\right.\right. \\
& P\left(\theta \geqslant \theta^{*} \mid x^{*}>1+\eta-\varepsilon\right) P\left(x^{*}>1+\eta-\varepsilon\right) .
\end{aligned}
$$

The first element on the right hand side is

$$
\left(\frac{x+\varepsilon-\theta^{*}}{x+\varepsilon+\eta}\right)\left(\frac{-\eta+\varepsilon-(-\eta-\varepsilon)}{1+2 \eta+2 \varepsilon}\right)=\left(\frac{x+\varepsilon-\theta^{*}}{x+\varepsilon+\eta}\right)\left(\frac{2 \varepsilon}{1+2 \eta+2 \varepsilon}\right) .
$$

The second,

$$
\left(\frac{x^{*}+\varepsilon-\theta^{*}}{2 \varepsilon}\right)\left(\frac{1+\eta-\varepsilon-(-\eta+\varepsilon)}{1+2 \eta+2 \varepsilon}\right)=\left(\frac{x^{*}+\varepsilon-\theta^{*}}{2 \varepsilon}\right)\left(\frac{1+2 \eta-2 \varepsilon}{1+2 \eta+2 \varepsilon}\right) .
$$

Finally, the third element is,

$$
\left(\frac{1+\eta-\theta^{*}}{1-x+\varepsilon+\eta}\right)\left(\frac{1+\eta+\varepsilon-(1+\eta-\varepsilon)}{1+2 \eta+2 \varepsilon}\right)=\left(\frac{1+\eta-\theta^{*}}{1-x+\varepsilon+\eta}\right)\left(\frac{2 \varepsilon}{1+2 \eta+2 \varepsilon}\right) .
$$

The conditional probability is

$$
P\left(\theta \geqslant \theta^{*} \mid x^{*}\right)=\frac{1+2 \eta-2 \varepsilon}{1+2 \eta+2 \varepsilon}\left(\frac{x^{*}+\varepsilon-\theta^{*}}{2 \varepsilon}\right)+\frac{2 \varepsilon}{1+2 \eta-2 \varepsilon}\left(\frac{x^{*}+\varepsilon-\theta^{*}}{x^{*}+\varepsilon+\eta}+\frac{1+\eta-\theta^{*}}{1-x^{*}+\varepsilon+\eta}\right)
$$

Recall the Profit condition,

$$
P\left(\theta \geqslant \theta^{*} \mid x^{*}\right)=\mu .
$$

This equation, combined with the conditional probability above delivers equation (2) in the text. 


\section{Uniqueness}

The two equations determining the two equilibrium values, $x^{*}$ and $\theta^{*}$ are

$$
\theta^{*}=\lambda s+(1-\lambda) s \frac{x^{*}+\varepsilon-\theta^{*}}{2 \varepsilon}=f\left(\theta^{*}\right),
$$

and

$$
P\left(\theta \geqslant \theta^{*} \mid x^{*}\right)=\mu . \quad(P C)
$$

Define $g(\mu, \theta(\eta, \varepsilon), x(\eta, \varepsilon), \delta, \varepsilon)=P\left(\theta \geqslant \theta^{*} \mid x^{*}\right)-\mu$.

The necessary condition for existence and uniqueness for $\theta^{*}$ and $x^{*}$ is,

$$
\frac{\partial x_{P C}}{\partial \theta_{P C}} \leq 1+\frac{2 \varepsilon \lambda}{(1-\lambda) s}=\frac{\partial x_{M C}}{\partial \theta_{M C}} .
$$

The implicit function theorem (IFT for short) will be used to show that the solu-

tion, when the precision of the public, $\delta=\frac{1}{\eta}$, is arbitrarily small, is unique. If at a point $\left(\theta\left(\delta_{0}, \varepsilon_{0}\right), x\left(\delta_{0}, \varepsilon_{0}\right), \delta_{0}, \varepsilon_{0}\right), g(\mu, \theta(\eta, \varepsilon), x(\eta, \varepsilon), \delta, \varepsilon)=0, \frac{\partial g(\mu, \theta(\eta, \varepsilon), x(\eta, \varepsilon), \delta, \varepsilon)}{\partial \theta} \neq$ 0 , and $\frac{\partial g(\mu, \theta(\eta, \varepsilon), x(\eta, \varepsilon), \delta, \varepsilon)}{\partial x} \neq 0$. Then, by the IFT,

$$
\frac{\partial x}{\partial \theta}=-\frac{\frac{\partial g(\mu, \theta(\eta, \varepsilon), x(\eta, \varepsilon), \delta, \varepsilon)}{\partial \theta}}{\frac{\partial g(\mu, \theta(\eta, \varepsilon), x(\eta, \varepsilon), \delta, \varepsilon)}{\partial x}}
$$

First calculate the two derivatives,

$\frac{\partial g(\mu, \theta(\eta, \varepsilon), x(\eta, \varepsilon), \delta, \varepsilon)}{\partial x}=\frac{1}{2 \varepsilon}\left(\frac{1+\frac{2}{\delta}-2 \varepsilon}{1+\frac{2}{\delta}+2 \varepsilon}\right)+\frac{2 \varepsilon}{1+\frac{2}{\delta}+2 \varepsilon}\left(\frac{\frac{1}{\delta}+\theta}{\left(x+\varepsilon+\frac{1}{\delta}\right)^{2}}+\frac{1+\frac{1}{\delta}+x}{\left(1-x+\varepsilon+\frac{1}{\delta}\right)^{2}}\right)$, and

$\frac{\partial g(\mu, \theta(\eta, \varepsilon), x(\eta, \varepsilon), \delta, \varepsilon)}{\partial \theta}=-\frac{1}{2 \varepsilon}\left(\frac{1+\frac{2}{\delta}-2 \varepsilon}{1+\frac{2}{\delta}+2 \varepsilon}\right)-\frac{2 \varepsilon}{1+\frac{2}{\delta}+2 \varepsilon}\left(\frac{1}{\left(x+\varepsilon+\frac{1}{\delta}\right)}+\frac{1}{\left(1-x+\varepsilon+\frac{1}{\delta}\right)}\right)$.

In the limit, $\lim _{\delta \rightarrow 0} \frac{\partial g(\mu, \theta(\eta, \varepsilon), x(\eta, \varepsilon), \delta, \varepsilon)}{\partial x}=-\frac{1}{2 \varepsilon}$, and $\lim _{\delta \rightarrow 0} \frac{\partial g(\mu, \theta(\eta, \varepsilon), x(\eta, \varepsilon), \delta, \varepsilon)}{\partial \theta}=$ $-\frac{1}{2 \varepsilon}$. Clearly, the solution is unique, $\lim _{\delta \rightarrow 0} \frac{\partial x_{P C}}{\partial \theta_{P C}}=1 \leq 1+\frac{2 \varepsilon \lambda}{(1-\lambda) s}$.

By the implicit function theorem $\frac{\partial \theta\left(\delta, \varepsilon_{0}\right)}{\partial \delta}$ and $\frac{\partial x\left(\delta, \varepsilon_{0}\right)}{\partial \delta}$ exist, so that $\theta\left(\delta, \varepsilon_{0}\right)$ and $x\left(\delta, \varepsilon_{0}\right)$ are continuous in $\delta$. Next, by the continuity of $g\left(\mu, \theta\left(\delta, \varepsilon_{0}\right), x\left(\delta, \varepsilon_{0}\right), \delta, \varepsilon_{0}\right)$ in $\delta$, there is an interval around $\left(\theta\left(\delta_{0}, \varepsilon_{0}\right), x\left(\delta_{0}, \varepsilon_{0}\right), \delta_{0}, \varepsilon_{0}\right)$ where a solution exists, and approaches to $\left(\theta\left(\delta_{0}, \varepsilon_{0}\right), x\left(\delta_{0}, \varepsilon_{0}\right)\right)$ as $\delta \rightarrow \delta_{0}$. For arbitrarily small public precision a unique equilibrium exists. Note that $\delta_{0}=0$ implies $\frac{x^{*}+\varepsilon-\theta^{*}}{2 \varepsilon}=\mu$.

For the sake of completeness, it will be shown that the result above holds without resorting to limiting arguments. This amounts to show that there is an lower bound for $\eta$ and therefore an upper bound for $q=\frac{\varepsilon}{\eta}$, such that $\frac{\partial x_{P C}}{\partial \theta_{P C}} \leq 1+\frac{2 \varepsilon \lambda}{(1-\lambda) s}$. It suffices to show the existence of an upper bound on $q$ so that, $\frac{\partial g(\mu, \theta(\eta, \varepsilon), x(\eta, \varepsilon), \delta, \varepsilon)}{\partial x} \neq 0, \frac{\partial g(\mu, \theta(\eta, \varepsilon), x(\eta, \varepsilon), \delta, \varepsilon)}{\partial \theta} \neq 0$, and,

$$
\frac{\partial x_{P C}}{\partial \theta_{P C}}=\frac{\frac{1}{2 \varepsilon}\left(\frac{1+\frac{2}{\delta}-2 \varepsilon}{1+\frac{2}{\delta}+2 \varepsilon}\right)+\frac{2 \varepsilon}{1+\frac{2}{\delta}+2 \varepsilon}\left(\frac{1}{\left(x+\varepsilon+\frac{1}{\delta}\right)}+\frac{1}{\left(1-x+\varepsilon+\frac{1}{\delta}\right)}\right)}{\frac{1}{2 \varepsilon}\left(\frac{1+\frac{2}{\delta}-2 \varepsilon}{1+\frac{2}{\delta}+2 \varepsilon}\right)+\frac{2 \varepsilon}{1+\frac{2}{\delta}+2 \varepsilon}\left(\frac{\frac{1}{\delta}+\theta}{\left(x+\varepsilon+\frac{1}{\delta}\right)^{2}}+\frac{1+\frac{1}{\delta}+x}{\left(1-x+\varepsilon+\frac{1}{\delta}\right)^{2}}\right)}<1+\frac{2 \varepsilon \lambda}{(1-\lambda) s}
$$


The first two conditions are true as long as $\varepsilon \neq \frac{1}{\delta}=\eta$. For the last to hold,

$$
\begin{aligned}
& \frac{\lambda s}{(1-\lambda) s}\left(\frac{1+\frac{2}{\delta}-2 \varepsilon}{1+\frac{2}{\delta}+2 \varepsilon}\right)+\frac{2 \varepsilon}{1+\frac{2}{\delta}+2 \varepsilon}\left(\frac{\frac{1}{\delta}+\theta}{\left(x+\varepsilon+\frac{1}{\delta}\right)^{2}}+\frac{1+\frac{1}{\delta}+x}{\left(1-x+\varepsilon+\frac{1}{\delta}\right)^{2}}\right)\left(1+\frac{2 \varepsilon \lambda}{(1-\lambda) s}\right) \\
> & \frac{2 \varepsilon}{1+\frac{2}{\delta}+2 \varepsilon}\left(\frac{1}{\left(x+\varepsilon+\frac{1}{\delta}\right)}+\frac{1}{\left(1-x+\varepsilon+\frac{1}{\delta}\right)}\right) .
\end{aligned}
$$

As then $\frac{\partial x_{P C}}{\partial \theta_{P C}}<1$.

Note that as $\varepsilon \rightarrow 0$ the inequality becomes $\frac{\lambda s}{(1-\lambda) s}>0 \forall \delta$. The same is true as $\delta \rightarrow 0$. Additionally both sides of the inequality are continuous $\forall \varepsilon$ and $\forall \delta \neq 0$. Clearly $\forall \delta \quad \exists \bar{\varepsilon}$ s.t. $\forall \varepsilon<\bar{\varepsilon}$ the above inequality holds.

\section{The Kuhn-Tucker Program of the Government}

Using the functional forms posted in the text the Government's problem is

$$
\begin{gathered}
\max _{s} F(I)\left(\frac{1+\eta-\lambda s-\mu s+\lambda \mu s}{1+2 \eta}\right)-\left(c S+c_{2} I\right)\left(\frac{\lambda s+\mu s-\lambda \mu s+\eta}{1+2 \eta}\right)-s I-\frac{(1-s) I}{1+\lambda \kappa-\lambda} \\
\text { s.t. } s \geqslant 0 \\
s \leq 1
\end{gathered}
$$

The complementary slackness conditions for this problem are

$$
\begin{array}{rlrl}
\frac{\partial L}{\partial s} & \leq 0 & s \geqslant 0 & s \frac{\partial L}{\partial s}=0 \\
s & \leq 1 & m^{L} \geqslant 0 & m^{L}(1-s)=0
\end{array}
$$

Substituting by the relevant functional forms this becomes,

$$
\begin{gathered}
-F(I) \Gamma-c I\left(\Gamma s+\frac{\eta}{1+2 \eta}\right)-\left(c S+c_{2} I\right) \Gamma-I+\frac{I}{1+\lambda \kappa-\lambda}-m^{L} \leq 0, \\
s \geqslant 0, \\
s\left[-F(I) \Gamma-c I\left(\Gamma s+\frac{\eta}{1+2 \eta}\right)-\left(c S+c_{2} I\right) \Gamma-I+\frac{I}{1+\lambda \kappa-\lambda}-m^{L}\right]=0,
\end{gathered}
$$

and,

$$
\begin{gathered}
s \leq 1, \\
m^{L} \geqslant 0, \\
m^{L}(1-s)=0 .
\end{gathered}
$$

where $\left(\frac{\lambda+\mu-\lambda \mu}{1+2 \eta}\right)=\Gamma$.

Using equation $(A 3)$, if $s>0$ then

$$
-F(I) \Gamma-c I\left(\Gamma s+\frac{\eta}{1+2 \eta}\right)-\left(c S+c_{2} I\right) \Gamma-I+\frac{I}{1+\lambda \kappa-\lambda}=m^{L}
$$

If in addition, $s<1$, then from equation $(A 6), m^{L}=0$ must hold. This can be substituted back into $(A 7)$ to give

$$
-F(I) \Gamma-c I\left(\Gamma s+\frac{\eta}{1+2 \eta}\right)-\left(c S+c_{2} I\right) \Gamma-I+\frac{I}{1+\lambda \kappa-\lambda}=0
$$


which gives the interior solution reported in the article.

Regarding the corner solutions. Focusing first in case in which $s=1$. Again, use $(A 6)$ to get $m^{L}>0$. In addition, $(A 3)$ can be used after substituting $s=1$ to get

$$
m^{L}=-F(I) \Gamma-c I\left(\Gamma+\frac{\eta}{1+2 \eta}\right)-\left(c+c_{2}\right) I \Gamma-I+\frac{I}{1+\lambda \kappa-\lambda}>0,
$$

which implies

$$
-F(I) \Gamma-\left(2 c+c_{2}\right) I \Gamma+-\frac{c I \eta}{1+2 \eta}+\frac{(\lambda-\lambda \kappa) I}{1+\lambda \kappa-\lambda}>0
$$

as stated in the text.

Finally, if $s=0$ is a solution to the government's problem then, from equation $(A 1)$ it is evident that $\left.\frac{\partial L}{\partial s}\right|_{s=0}<0$. Using this, and the fact that $(A 6)$ implies $m^{L}=0$, equation $(A 3)$ becomes

$$
-F(I) \Gamma-\frac{c I \eta}{1+2 \eta}-c_{2} I \Gamma+\frac{(\lambda-\lambda \kappa) I}{1+\lambda \kappa-\lambda}<0,
$$

which ends the proof. 


\section{References}

[1] Bannier, C. (2005), "Big Elephants in Small Ponds: Do Large Traders Make Financial Markets More Aggressive?". Journal of Monetary Economics, vol. 52 .

[2] Barro, R. and J.W. Lee (2005), "IMF programs: Who is chosen and what are the effects?". Journal of Monetary Economics, vol. 52.

[3] Birds G., and D. Rowlands (2002), " "Do IMF Programmes Have a Catalytic Effect on Other International Capital Flows?", Oxford Development Studies, Vol. 30, No. 3.

[4] Broner, F., Lorenzoni, G. and S. Schmukler (2004), "Why Do Emerging Countries Borrow Short Term?", NBER Working Papers 13076.

[5] Broto, C., Diaz-Cassou, J. and A. Erce (2011), " "Measuring and explaining the volatility of capital flows towards emerging countries". Journal of Banking and Finance - Volume 35 (8)

[6] Bussiere, M. and A. Ristiniemi (2012), "Credit Ratings and Debt Crises". Mimeo

[7] Caballero, R., and A. Krishnamurthy (2000), "Dollarization of Liabilities: Underinsurance and Domestic Financial Underdevelopment". NBER Working Paper No. 7792.

[8] Chang, R. and A. Velasco (2000), "Banks, Debt Maturity and Financial Crises". Journal of International Economics 51.

[9] Copelovich, M. (2004), "Private Debt Composition and teh Political Economy of IMF Lending"

[10] Corsetti, G., Guimaraes, B. and N. Roubini (2006), "International lending of last resort and moral hazard. A model of IMF's catalytic finance". Journal of Monetary Economics, vol. 53(3).

[11] De Resende, C. (2007), "IMF-Supported Adjustment Programs: Welfare Implications and the Catalytic Effect". Bank of Canada, Working Paper No. 2007-22.

[12] Diamond, D.W. and P.H. Dybvig (1983), "Bank Runs, Deposit Insurance, and Liquidity". Journal of Political Economy 91.

[13] Diamond, D. W. (1991), "Debt Maturity Structure and Liquidity Risk". Quarterly Journal of Economics, vol. 103, No. 3.

[14] Diaz-Cassou, J., Molina, L., and A. Garcia-Herrero (2006), "What Kind of Flows Does the IMF Catalyze and When?". Bank of Spain Working Paper, No. 0617.

[15] Dreher, A., and R. Vaubel (2004), " Do IMF and IBRD cause moral hazard and political business cycles? Evidence from panel data". Open Economies Review 15(1). 
[16] Dreher, A. and J. Sturm (2006), "Do IMF and World Bank Influence Voting in the UN General Assembly?". KOF Working Paper 137.

[17] Edwards, M. (2003), "Signaling credibility? The IMF and catalytic finance", Mimeo.

[18] Edwards, S. asn J.A. Santaella (1993), "Devaluation controversies in the developing countries: lessons from the Bretton Woods era". In "A restrospective on the BRetton Woods System:Lessons for International Monetary Reform", University of Chicago Press.

[19] Eichengreen, B. and A. Mody (1998), "What Explains Changing Spreads on Emerging Market Debt: Fundamentals or Market Sentiment?". NBER Working Papers, No. 6408.

[20] Eichengreen, B. and A. Mody (2003), "Bail Ins, Bailouts, and Borrowing Costs", Journal of Econometrics, Vol. 36.

[21] Eichengreen, B., Kletzer and A. Mody (2005), "The IMF in a World of Private Capital Markets", IMF Working Paper 05/84.

[22] Eichengreen, B., Hale, G. and A. Mody (2001), "Flight to Quality: Investors Risk Tolerance and the Spread of Emerging Market Crises", in International Financial Contagion: How it spreads and how it can be stopped, edited by Stijn Claessens and Kristin Forbes, Kluwer Academic Publishers.

[23] Erce, A. (2008). "A Structural Model of Sovereign Debt Issuance: Assessing the Role of Financial Factors". Bank of Spain Working Paper, No. 0809.

[24] Gosh, A, Lane, T. , Schultze-Gattas, M., Bulir, A., Hasmann, J. and A. Mourmouras (2002), "IMF Supported Programs in Capital Account Crises" IMF Occasional Paper No. 210.

[25] Jeanne, O. (2000), "Debt Maturity and the Global Financial Architecture". CEPR Discussion Paper No. 2520.

[26] Jeanne, O. (2009), "Debt Maturity and the International Financial Architecture". American Economic Review, 99(5)..

[27] Kharroubi, E. (2004), "Liquidity, Volatility and Growth". DELTA Working Papers 2004-26.

[28] Laeven, L., and F. Valencia (2008), "Systemic Banking Crises: A New Database". IMF Working Paper No. 08/224.

[29] Martin, B. and A. Peñalver (2002), "The Effect of Payments Standstills on Yields and the Maturity Structure of Sovereign Debt". Bank of England, Working Paper No. 184.

[30] Min, H., Lee, D., Nam, C., Park, M. and S. Nam (2003), "Determinants of Emerging Market Spreads: Cross Country Evidence". Global Finance Journal 14.

[31] Mina, W. and J. Martinez-Vazquez (2002), "IMF Lending, Maturity of International Debt and Moral Hazard". Georgia State University Working Paper, No. 03-01 
[32] Mody, A., and D. Saravia (2003) "Catalyzing Private Capital Flows: Do IMF-Supported Programs Work asCommitment Devices?", IMF Working Paper 03/100.

[33] Morris, S. and H. Shin (1998), "Unique Equilibrium in a Model of SelfFulfilling Attacks". American Economic Review 88.

[34] Morris, S. and H. Shin (2004), "Coordination Risk and the Price of Debt". European Economic Review 48.

[35] Morris, S. and H. Shin (2006), "Catalytic Finance: When Does it Work?". Journal of International Economics, vol. 70(1).

[36] Rochet, J.C:, and X. Vives (2004), "Coordination Failures and the Lender of Last Resort : Was Bagehot Right After All?". Journal of the European Economic Association, vol. 2(6)

[37] Narag, R. (2004), "The Term Structure and Default Risk in Emerging Markets". Working Paper, UCLA.

[38] Rodrick, D. and A. Velasco (1999), "Short-Term Capital Flows". Prepared for the ABCDE Conference at the World Bank.

[39] Peñalver, A. (2004), "How can the IMF catalyse private capital flows? A model". Bank of England, Working Paper No. 215.

[40] Saravia, D. (2010), "Vulnerability, Crisis and Debt Management: Do IMF Interventions Shorten the Lenght of Borrowing?". Central Bank of Chile, Working Paper N0. 600.

[41] Shin, H. (2001), "Coordination and the Term Structure of Interest Rates for Defaultable Securities". Mimeo.

[42] Thacker, S. (2000), "The high politics of IMF lending". World Politics, 52.

[43] Zwart, S. (2007), "The Mixed Blessing of IMF Intervention: Signalling versus Liquidity Support". Journal of Financial Stability, 3(2). 


\section{Appendix}

\begin{tabular}{cc} 
& Country list \\
\hline Argentina & Lithuania \\
Belize & Malaysia \\
Brazil & Malta \\
Bulgaria & Mexico \\
Chile & Morocco \\
China & Pakistan \\
Colombia & Panama \\
Costa Rica & Peru \\
Croatia & Philippines \\
Cyprus & Poland \\
Czech Republic & Romania \\
Dominican Republic & Russian Federation \\
Ecuador & Singapore \\
Egypt & Slovak Republic \\
El Salvador & Slovenia \\
Estonia & South Africa \\
Hungary & Taiwan \\
India & Thailand \\
Indonesia & Trinidad and Tobago \\
Kazakhstan & Tunisia \\
Korea & Turkey \\
Latvia & Uruguay \\
Lebanon & Venezuela \\
\hline & \\
\hline &
\end{tabular}


Figure 1

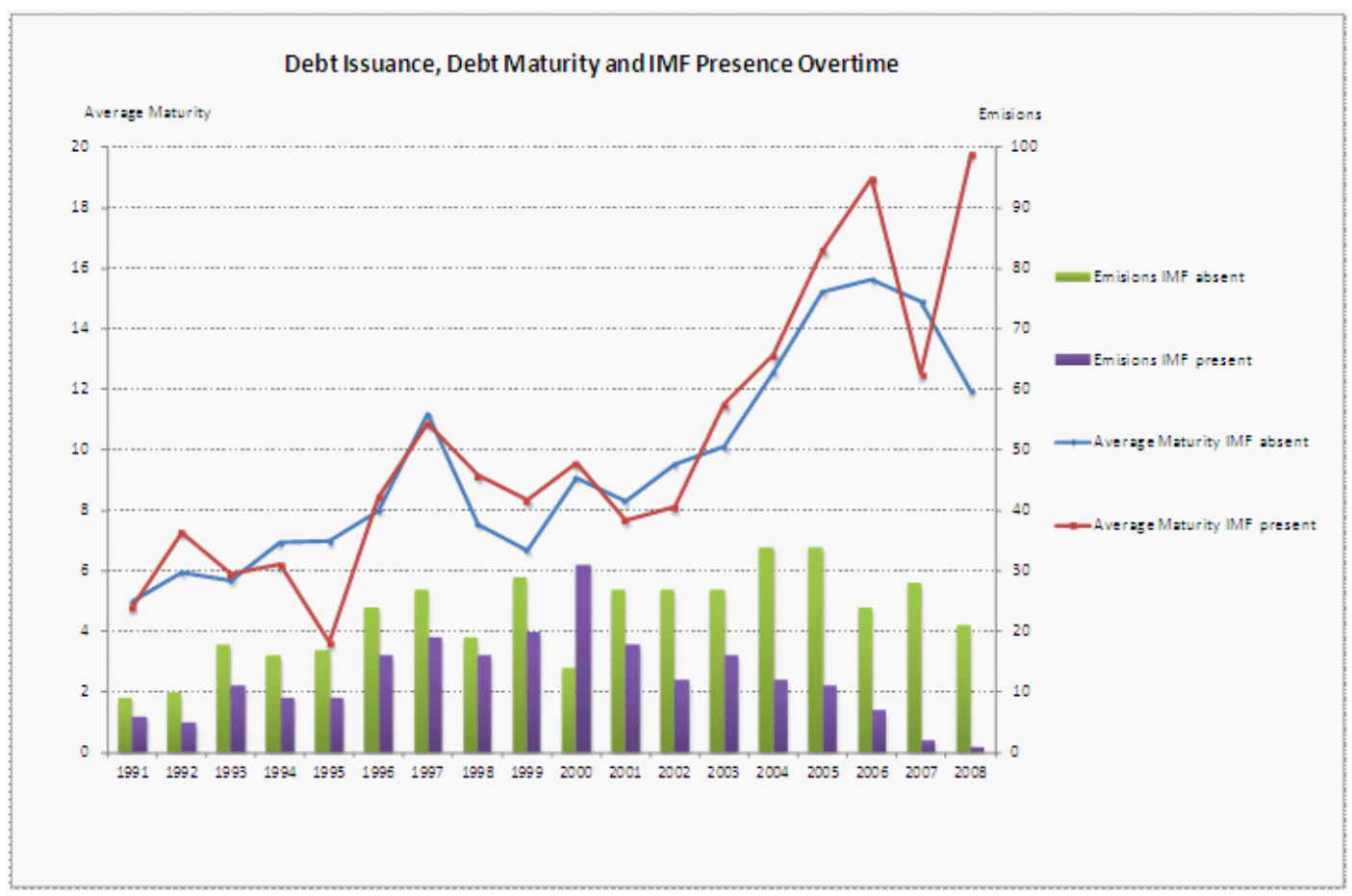


Table A.1

\section{Correlation matrix}

\begin{tabular}{|c|c|c|c|c|c|c|}
\hline & $\begin{array}{l}\text { weighted } \\
\text { maturity }\end{array}$ & $\begin{array}{c}\text { weighted } \\
\text { spread }\end{array}$ & rating & $\begin{array}{c}\text { Global } \\
\text { liquidity } \\
\text { HY }\end{array}$ & $\begin{array}{c}\text { Global } \\
\text { liquidty } \\
\text { Quantities }\end{array}$ & $\begin{array}{c}\text { Reserves } \\
\text { to } \\
\text { imports }\end{array}$ \\
\hline weighted maturity & 1 & & & & & \\
\hline weighted spread & 0.5673 & 1 & & & & \\
\hline rating & -0.115 & -0.1969 & 1 & & & \\
\hline Global liquidity HY & 0.042 & -0.1085 & 0.0591 & 1 & & \\
\hline $\begin{array}{c}\text { Global liquidty } \\
\text { Quantities }\end{array}$ & 0.0052 & -0.0808 & 0.0233 & 0.8746 & 1 & \\
\hline Reserves to imports & -0.0038 & 0.0251 & -0.004 & 0.1405 & 0.1254 & 1 \\
\hline
\end{tabular}

Table A.2

Debt Maturity During and Around Crises

\begin{tabular}{ccccc}
\hline \hline & & IMF Present & IMF Absent & Ratio \\
\hline \hline \multirow{3}{*}{ Bank Crisis } & Mean & 9.77 & 10.30 & 0.95 \\
& Standard deviation & 8.21 & 6.68 & 1.23 \\
& No. of observations & 39 & 24 & 1.63 \\
\hline \hline \multirow{3}{*}{ Debt Crisis } & Mean & 11.70 & 14.44 & 0.81 \\
& Standard deviation & 7.59 & 8.85 & 0.86 \\
& No. of observations & 16.00 & 16.00 & 1.00 \\
\hline \hline \multirow{3}{*}{ No Crisis } & Mean & 10.46 & 10.84 & 0.96 \\
& Standard deviation & 6.65 & 6.94 & 0.96 \\
& No. of observations & 130 & 284 & 0.46 \\
\hline \hline
\end{tabular}

The table shows weighted average maturity in debt crisis, bank crisis and no crises periods. No crises periods refer to periods not classified as any of the others. Debt maturity is measured in quarters. The sample period is from 1995 to 2008. 
Determinants of IMF presence

\begin{tabular}{|c|c|c|c|}
\hline VARIABLES & Panel Probit IMF & Panel Probit SBA & Panel Program size \\
\hline Credit rating & $-2.811 \mathrm{e}-01 * * *$ & $-1.661 \mathrm{e}-01 * * *$ & $-7.871 \mathrm{e}-05 * * *$ \\
\hline Debt crisis dummy & $\begin{array}{c}{[0.03]} \\
3.726 e-01 \\
{[0.23]}\end{array}$ & $\begin{array}{c}{[0.03]} \\
-1.207 \mathrm{e}-01 \\
{[0.21]}\end{array}$ & $\begin{array}{c}{[0.00]} \\
1.451 \mathrm{e}-04 \\
{[0.00]}\end{array}$ \\
\hline Bank crisis dummy & $\begin{array}{c}2.560 \mathrm{e}-01 * \\
{[0.14]}\end{array}$ & $\begin{array}{c}3.327 \mathrm{e}-01 \text { 1** } \\
{[0.14]}\end{array}$ & $\begin{array}{c}1.472 \mathrm{e}-03 * * * \\
{[0.00]}\end{array}$ \\
\hline Voting along the US at the UN & $\begin{array}{c}4.425 \mathrm{e}+00 * * \\
{[2.17]}\end{array}$ & $\begin{array}{c}3.478 \mathrm{e}+00^{* * *} \\
{[1.73]}\end{array}$ & $\begin{array}{c}1.227 \mathrm{e}-03 \\
{[0.00]}\end{array}$ \\
\hline IMF total BA (SDR millions) & $\begin{array}{c}1.037 \mathbf{e}-03 * * * \\
{[0.00]}\end{array}$ & $\begin{array}{c}4.480 \mathrm{e}-04 * * * \\
{[0.00]}\end{array}$ & $\begin{array}{c}-2.533 \mathrm{e}-07 \\
{[0.00]}\end{array}$ \\
\hline IMF total quota (SDR millions) & $\begin{array}{c}-\mathbf{2 . 4 8 9 e - 0 4} * * * \\
{[0.59]}\end{array}$ & $\begin{array}{c}-1.066 \mathrm{e}-04 * * * \\
{[0.57]}\end{array}$ & $\begin{array}{c}5.890 \mathrm{e}-08 \\
{[0.00]}\end{array}$ \\
\hline IMF available resources (SDR millions) & $\begin{array}{c}-1.817 \mathrm{e}-01 \\
{[0.59]}\end{array}$ & $\begin{array}{c}4.477 \mathrm{e}-01 \\
{[0.57]}\end{array}$ & $\begin{array}{c}2.338 \mathrm{e}-03 * * \\
{[0.00]}\end{array}$ \\
\hline Country's quota (\% total) & $\begin{array}{c}-2.803 \mathrm{e}-03 \\
{[0.34]}\end{array}$ & $\begin{array}{c}-1.800 \mathrm{e}-01 \\
{[0.27]}\end{array}$ & $\begin{array}{c}3.063 \mathrm{e}-05 \\
{[0.00]}\end{array}$ \\
\hline Paris Club treatment dummy & $\begin{array}{c}9.346 \mathrm{e}-01 \text { 1** } \\
{[0.48]}\end{array}$ & $\begin{array}{c}3.645 \mathrm{e}-01 \\
{[0.40]}\end{array}$ & $\begin{array}{c}2.709 \mathrm{e}-\mathbf{0 3} * * * \\
{[0.00]}\end{array}$ \\
\hline Democratic regime dummy & $\begin{array}{c}\mathbf{- 5 . 8 1 2 e - 0 1 * *} \\
{[0.23]}\end{array}$ & $\begin{array}{c}\mathbf{- 8 . 5 6 6 e - 0 1} * * * \\
{[0.21]}\end{array}$ & $\begin{array}{c}9.446 \mathrm{e}-05 \\
{[0.00]}\end{array}$ \\
\hline Constant & $\begin{array}{c}1.788 \mathrm{e}+01 * * * \\
{[2.23]}\end{array}$ & $\begin{array}{c}6.690 \mathrm{e}+00 * * * \\
{[2.02]}\end{array}$ & $\begin{array}{c}-3.728 \mathrm{e}-03 \\
{[0.00]}\end{array}$ \\
\hline Observations & 2276 & 2276 & 2276 \\
\hline
\end{tabular}

Table 1 
Weighted average maturity

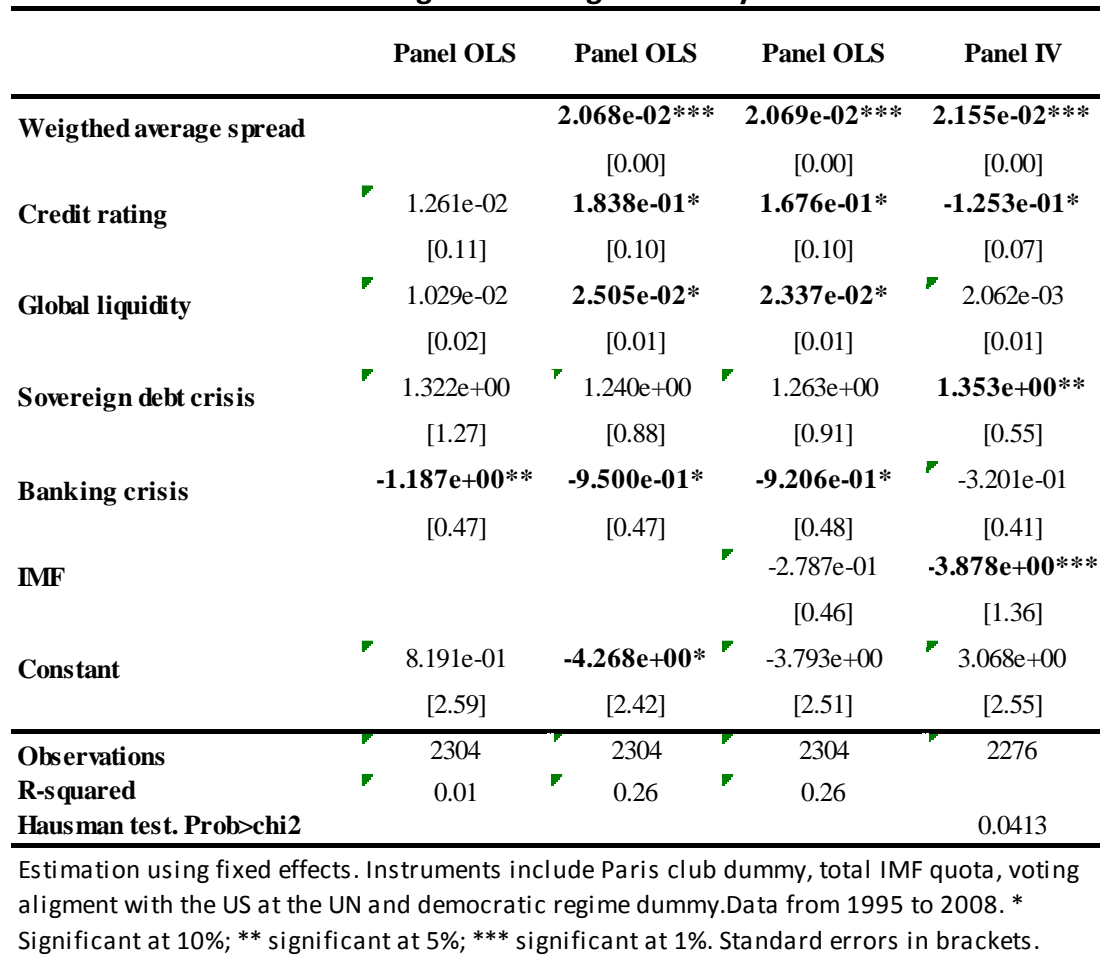

Table 2.a 
Weighted average maturity. Robustness

\begin{tabular}{|c|c|c|c|c|}
\hline & $\begin{array}{c}\text { Panel with } \\
\text { program type }\end{array}$ & $\begin{array}{l}\text { Panel IV with } \\
\text { program type }\end{array}$ & $\begin{array}{c}\text { Panel with } \\
\text { program size }\end{array}$ & $\begin{array}{l}\text { Panel IV with } \\
\text { program size }\end{array}$ \\
\hline Weigthed average spread & $2.072 \mathrm{e}-02 * * *$ & $2.154 \mathrm{e}-02 * * *$ & $2.069 \mathrm{e}-02 * * *$ & $2.176 \mathrm{e}-02 * * *$ \\
\hline Credit rating & $\begin{array}{c}{[0.00]} \\
1.523 \mathrm{e}-01 \\
{[0.10]}\end{array}$ & $\begin{array}{c}{[0.00]} \\
-1.111 \mathrm{e}-01 \\
{[0.07]}\end{array}$ & $\begin{array}{c}{[0.00]} \\
\mathbf{1 . 8 0 6 e - 0 1} * \\
{[0.10]}\end{array}$ & $\begin{array}{c}{[0.00]} \\
-5.653 \mathrm{e}-02 \\
{[0.07]}\end{array}$ \\
\hline Global liquidity & $\begin{array}{c}2.201 \mathrm{e}-02 \\
{[0.01]}\end{array}$ & $\begin{array}{c}3.236 \mathrm{e}-03 \\
{[0.01]}\end{array}$ & $\begin{array}{c}2.490 \mathrm{e}-02 \\
{[0.01]}\end{array}$ & $\begin{array}{c}1.720 \mathrm{e}-02 \\
{[0.01]}\end{array}$ \\
\hline Sovereign debt crisis & $\begin{array}{c}1.412 \mathrm{e}+00 \\
{[0.89]}\end{array}$ & $\begin{array}{c}1.866 \mathrm{e}+00 * * * \\
{[0.62]}\end{array}$ & $\begin{array}{c}1.243 \mathrm{e}+00 \\
{[0.89]}\end{array}$ & $\begin{array}{c}1.193 \mathrm{e}+00 \\
{[0.64]}\end{array}$ \\
\hline Banking crisis & $\begin{array}{c}-9.265 \mathrm{e}-01 * * \\
{[0.46]}\end{array}$ & $\begin{array}{c}-5.217 \mathrm{e}-01 \\
{[0.42]}\end{array}$ & $\begin{array}{c}-9.270 e-01 * \\
{[0.48]}\end{array}$ & $\begin{array}{c}5.014 \mathrm{e}-01 \\
{[0.73]}\end{array}$ \\
\hline IMF & $\begin{array}{c}-\mathbf{1 . 0 8 5 e}+00 * \\
{[0.59]}\end{array}$ & $\begin{array}{c}\mathbf{6 . 6 3 3 e}+00 * * * \\
{[2.05]}\end{array}$ & & \\
\hline SBA & $\begin{array}{c}\mathbf{1 . 0 5 7} \mathbf{e}+\mathbf{0 0} * \\
{[0.62]}\end{array}$ & $\begin{array}{c}5.514 \mathrm{e}+00 * \\
{[3.11]}\end{array}$ & & \\
\hline IMF program size & & & $\begin{array}{c}-1.759 e+01 \\
{[23.13]}\end{array}$ & $\begin{array}{c}\mathbf{- 9 . 3 9 7 e + 0 2} * * \\
{[429.03]}\end{array}$ \\
\hline Constant & $\begin{array}{c}-3.435 \mathrm{e}+00 \\
{[2.53]}\end{array}$ & $\begin{array}{c}2.449 \mathrm{e}+00 \\
{[2.55]}\end{array}$ & $\begin{array}{c}-4.210 \mathrm{e}+00 * \\
{[2.42]}\end{array}$ & $\begin{array}{c}-4.757 \mathrm{e}-01 \\
{[2.01]} \\
\end{array}$ \\
\hline $\begin{array}{l}\text { Observations } \\
\text { R-squared }\end{array}$ & $\begin{array}{l}2304 \\
0.26\end{array}$ & 2276 & $\begin{array}{l}2304 \\
0.26\end{array}$ & 2276 \\
\hline Hausman test. Prob>chi2 & & 0.0054 & & 0.016 \\
\hline
\end{tabular}

Estimation using fixed effects. Instruments include Paris club dummy, total IMF quota, voting aligment with the US at the UN and democratic regime dummy.Data from 1995 to 2008. *

Significant at $10 \%{ }^{* *}$ significant at $5 \%$; ${ }^{* * *}$ significant at $1 \%$. Standard errors in brackets.

Table 2.b 
Weighted Maturity. Heckman Model

\begin{tabular}{|c|c|c|c|}
\hline VARIABLES & $\begin{array}{l}\text { Sample Selection with } \\
\text { instrumented IMF }\end{array}$ & $\begin{array}{c}\text { Sample Selection } \\
\text { with instrumented } \\
\text { program types }\end{array}$ & $\begin{array}{c}\text { Sample Selection } \\
\text { with instrumented } \\
\text { program size } \\
\end{array}$ \\
\hline Average weighted spread & $\begin{array}{c}1.421 \mathrm{e}-03 \\
{[0.00]}\end{array}$ & $\begin{array}{c}1.542 \mathrm{e}-03 \\
{[0.00]}\end{array}$ & $\begin{array}{c}1.088 \mathrm{e}-03 \\
{[0.00]}\end{array}$ \\
\hline Credit rating & $\begin{array}{c}-1.016 e+00^{* * * *} \\
{[0.18]}\end{array}$ & $\begin{array}{c}-1.204 \mathrm{e}+00^{* * *} * \\
{[0.20]}\end{array}$ & $\begin{array}{c}-1.199 \mathrm{e}+00 * * * \\
{[0.18]}\end{array}$ \\
\hline Global liquidity & $\begin{array}{c}\mathbf{- 5 . 3 4 9 e - 0 2 *} \\
{[0.03]}\end{array}$ & $\begin{array}{c}-7.783 \mathrm{e}-02 \\
{[0.03]}\end{array}$ & $\begin{array}{c}\mathbf{- 5 . 6 5 2 e - 0 2} * * \\
{[0.03]}\end{array}$ \\
\hline Sovereign debt crisis & $2.135 \mathrm{e}-01$ & $2.012 \mathrm{e}+00$ & $1.072 \mathrm{e}+00$ \\
\hline & {$[1.68]$} & {$[1.81]$} & {$[1.70]$} \\
\hline Banking crisis & $\begin{array}{c}7.904 \mathrm{e}-01 \\
{[1.21]}\end{array}$ & $\begin{array}{c}6.812 \mathrm{e}-01 \\
{[1.20]}\end{array}$ & $\begin{array}{c}9.353 \mathrm{e}+00 * * * \\
{[2.66]}\end{array}$ \\
\hline IMF & $\begin{array}{c}\mathbf{- 1 . 1 8 2 e + 0 0} * * \\
{[0.55]}\end{array}$ & $\begin{array}{c}\mathbf{- 3 . 8 9 7} \mathbf{e}+00 * * * \\
{[1.23]}\end{array}$ & \\
\hline SBA & & $\begin{array}{c}3.445 \mathrm{e}+00^{* *} \\
{[1.41]}\end{array}$ & \\
\hline IMF program size & & & $\begin{array}{c}-\mathbf{6 . 3 0 0 e + 0 3} * * * \\
{[1663.55]}\end{array}$ \\
\hline Constant & $\begin{array}{c}\mathbf{1 . 1 1 8} \mathbf{e}+\mathbf{0 1} * * * \\
{[4.33]}\end{array}$ & $\begin{array}{c}\mathbf{1 . 8 0 5} \mathbf{e}+01 * * * \\
{[5.19]}\end{array}$ & $\begin{array}{c}1.689 \mathrm{e}+01 * * * * \\
{[4.80]}\end{array}$ \\
\hline Observations & 2156 & 2156 & 2156 \\
\hline Mills ratio & $\begin{array}{c}11.97 \\
{[0.504]} \\
\end{array}$ & $\begin{array}{l}11.85 \\
{[0.49]} \\
\end{array}$ & $\begin{array}{c}12.12 \\
{[0.501]} \\
\end{array}$ \\
\hline \multicolumn{4}{|c|}{ Selection equation. Issuance } \\
\hline Ratio of reserves to imports & $\begin{array}{c}\mathbf{8 . 7 7 5 e + 0 0} * * \\
{[4.12]}\end{array}$ & $\begin{array}{c}\mathbf{9 . 3 4 3 e + 0 0} * * \\
{[4.12]}\end{array}$ & $\begin{array}{c}5.235 \mathrm{e}+00 \\
{[3.85]}\end{array}$ \\
\hline Credit rating & $\begin{array}{c}\mathbf{- 8 . 3 4 4 e - 0 2} * * * \\
{[0.01]}\end{array}$ & $\begin{array}{c}-9.771 \mathrm{e}-02 * * * \\
{[0.02]}\end{array}$ & $\begin{array}{c}\mathbf{- 1 . 1 2 1 e - 0 1} * * * \\
{[0.01]}\end{array}$ \\
\hline Global liquidity & $\begin{array}{c}\mathbf{- 9 . 6 7 1 \mathrm { e } - 0 4} * * * \\
{[0.00]}\end{array}$ & $\begin{array}{c}-1.142 \mathrm{e}-03 * * * \\
{[0.00]}\end{array}$ & $\begin{array}{c}\mathbf{- 1 . 2 2 5 e - 0 3} * * * \\
{[0.00]}\end{array}$ \\
\hline Sovereign debt crisis & $\begin{array}{c}-1.172 \mathrm{e}-01 \\
{[0.13]}\end{array}$ & $\begin{array}{c}1.940 \mathrm{e}-02 \\
{[0.15]}\end{array}$ & $\begin{array}{c}-2.516 \mathrm{e}-02 \\
{[0.13]}\end{array}$ \\
\hline Banking crisis & $\begin{array}{c}1.371 \mathrm{e}-01 \\
{[0.10]}\end{array}$ & $\begin{array}{c}1.296 \mathrm{e}-01 \\
{[0.10]}\end{array}$ & $\begin{array}{c}7.621 \mathrm{e}-01 * * * \\
{[0.21]}\end{array}$ \\
\hline IMF & $\begin{array}{c}-1.686 \mathrm{e}-02 \\
{[0.10]}\end{array}$ & $\begin{array}{c}-2.231 \mathrm{e}-01 \\
{[0.10]}\end{array}$ & \\
\hline SBA & & $\begin{array}{c}2.612 \mathrm{e}-01 * * \\
{[0.12]}\end{array}$ & \\
\hline IMF program size & & & $\begin{array}{c}-\mathbf{4 . 5 1 4 e}+02 * * * \\
{[127.99]}\end{array}$ \\
\hline Constant & $\begin{array}{c}4.435 \mathrm{e}-01 * * * \\
{[0.17]}\end{array}$ & $\begin{array}{c}7.753 \mathrm{e}-01 * * * \\
{[0.24]}\end{array}$ & $\begin{array}{c}1.033 \mathbf{e}+00 * * * \\
{[0.20]}\end{array}$ \\
\hline$\overline{\text { Observations }}$ & 2156 & 2156 & 2156 \\
\hline
\end{tabular}

$5 \%$; *** significant at $1 \%$. Standard errors in brackets.

Table 3 